\title{
Psychological Resilience Exemplify in Children Stories
}

\author{
Ferril Irham Muzaki \\ Department of Elementary and Childhood Education, Faculty of Education, Universitas Negeri Malang, Indonesia
}

Received March 2, 2020; Revised April 14, 2020; Accepted April 27, 2020

Copyright $\bigcirc 2020$ by authors, all rights reserved. Authors agree that this article remains permanently open access under the terms of the Creative Commons Attribution License 4.0 International License

\begin{abstract}
Resilience capability is a part of elementary schools' student skill to create individual learning conformity. This study has four purposes; those are (1) to find problem dynamics in children short story, (2) to elaborate ethical values in children short stories, (3) to elaborate moral value in children short stories and (4) to find character education value in the short stories. The method that has been used in this study is cultural themes discovery. There are four results in this study; those are (1) resilience skills have characteristics to locate the trigger of the problem, (2) ability to anchor the problem, (3) ability to do strength analysis and (4) ability to do opportunity analysis. Thus, the resilience in facing the problems occurred in three eight circumstances, those are (1) self-conformity in learning process, (2) individuals' skills to adjust the topics, (3) self-adaptation process, (4) self-existence in the learning process, (5) self-actualization process, (6) self-acceptance, (7) cause and effect analysis and (8) problems interpretation. On the other hand, the learning process has to use metaphors to teach those skills in the classroom. The conclusion for this study is resilience is a part of psychological endurance in facing a problem. It is suggested for elementary schools' teachers to teach resilience and use children short stories.
\end{abstract}

Keywords Resilience, Children Short Story, Cultural Themes Discovery, Endurance the Problem, Elementary School Teacher

\section{Introduction}

Vale \& Campanella (2005:4) explain that mental resilience skills are needed for each student in elementary schools. Elementary schools' students have to learn meta-analysis for problems coping. The problems' coping capability in realistic circumstances is required for elementary schools' students. Elementary schools' students may face dilemmatic and problematic circumstances in their future life in order to learn problems' coping. Therefore, to gain maximum problems coping skills, concrete examples from children's stories are needed. Problems' coping based on resilience skills required to reflect the real problem in the future. Furthermore, the children's story to tell the example of mental resilience is obligated in elementary schools' classrooms. The mental resilience capabilities explained above have four categories.

A student who has resilience and capability understands the problems dynamic. The elementary schools' students have to learn the adaptation process in a condition near real life. Further, Vale \& Campanella (2005:4) explain that elementary school students have to acquire the resilience skills to resolve issues. The requirements on resilience in real life are conformity with others. Thus, conformity circumstances followed by the decrease in mental state for the individuals. Capability to conduct resilience is to adapt and deal with the problems. The performing actions in problems coping should be learned by the students. Students have to learn how to understand meta-analysis processes in terms of psychological resilience. Thus, the psychological resilience is characterized by the ability to restore mental conditions after experiencing decline phases.

The second capability in resilience is the ability in problems coping. Problems coping is acquired by the learning process for every individual. Ewert \& Yoshino (2011:35) state that the meta-analysis process for each individual has to be taught in early years. Thus, real-life required the ability to undertake the elaboration of the concept regarding the issues. Therefore, resilience capability has faced the opportunities to resolve the problem faced by students in the school years. The children's stories give examples of problems coping from the characters' conflict. The resilience topics in children short stories are obtained through discovery learning.

The third capability in resilience is ability to conduct a problems meta-analysis. The problems meta-analysis in strengthening character education should be taught at an early year. Sheffi (2005:1) explains the meta-analysis skills for elementary schools' students are capable of carrying 
out the problem in everyday life. Each student has to understand the concept resilience by looking at the short stories. The children's story based on psychological resilience is purposed to teach integrity.

The fourth capability in resilience is the ability to do problems mapping to solve problems. Randall, Baldwin, McKenize-Mhor, Mc Kim \& Furlong (2015:155) explain that in resilience, each individual has to be taught the conditions that are faced in real life. The disruptive circumstances are following psychological students' condition to develop acquisitions on resilience. Therefore, the children's stories that teach the values psychological resilience become the subject that is an example of resilience.

Resilience is a capability to mental struggle for elementary school students. Braga \& Mello (2012:134) state that capability for the individual to recover is a part resilience process. Thus, the capability for elementary schools' students to perform the meta-analysis follows the ability to resolve the problems. Resilience is a part of the mental skills for individuals to perform a meta-analysis in problems breakdown. Based on the explanation above, this study has the purpose to carry out the analysis in lines that exist in the psychological resilience that is contained in the children's stories.

\section{Materials and Methods}

This study used cultural themes discovery. This study used cultural themes discovery since this study is purposed to understand the content of psychological resilience which is spoken by the charters. The psychological resilience as the spoken text could be classified into small categories based on meaning of the words, phrase, or clause. According to Krippendorf (1984), the procedure in cultural themes discovery has five steps. Those steps are componential analysis, sampling, recording/coding, search similarity, and search universal themes.

The research data are phrases, clauses, and sentences of written text. The phrase data is a compound word that contains a short statement in the children's short story. The clause data is a clause containing a resilience message. The sentence data is a complete sentence that contains a resilience statement. Sources of data in this study are classic short stories, those are Cinderella, Father Frost, Jack and Beanstalk, Little Red Riding Hood, The Emperor New Clothes, Three Little Pigs, The Ugly Duckling and The Velveteen Rabbit. Those short stories are short stories that children had good reviews from. The children's short stories are collected from websites and various sources.

The instruments are phrases, clauses, and sentences corpus checklist designed objectively and systematically for identifying characteristics on communicational message based on communications factors. Those communication factors are speakers, code, media, purposes, and the situation in the conversation. The data collection is in three steps. Those steps are (1) to browse in short story criticism, (2) to download a short story that became the object of research, and (3) to observe the short story cuts in websites that are being uploaded by short story authors.

Data which have been collected from children's short stories are analyzed. This data analysis is using three steps. Those steps are (1) a large grouping of the messages that are in the children's short story, (2) codifying resilience statements in the children's short story, and (3) the synthesis of meaning implicates resilience statements that have been classified and codified. These three steps are undertaken to obtain a resilience message conveyed in the children's short story.

\section{Results and Discussion}

\subsection{Results}

In children's stories, there are four resilience skills exhibited by characters in children's stories. Those are the ability to analyze the problems' triggers, the ability to solve problems' anchor, the ability to do strength analysis and the ability to do opportunity analysis. The resilience skills above are explained below.

\subsection{The Ability to Locate Problems' Trigger}

Braga, Mello, et all (2012:135) state that the ability to analyze the problems' trigger is the capability to find the problems' root. In the analysis problems' trigger, skills are to find situations from the problems' root. The capability to analyze the problems root hand in hand with the capability to synthesize root of the problems. Another thing that is seen though is the skill to study from a root cause. The ability to conduct critical analysis problems is also a discussion topic along with the ability to conduct guided discoveries. Increased ability to conduct a study of developed situations is a part of the ability to find phenomena that problem development. The skill to conduct a problem discovery becomes a part of the ability to locate the triggers of a problem. It could be concluded that the ability finds problem sources.

"It happened that the King's son gave a ball, and invited all persons of fashion to it. Our young misses Also were invited, for they cut a very grand figure among the quality. "

In the sentence above, the phrase 's ability to cope the problem is a capability that is owned by a main character. In the phrase "cut a very grand among quality" is a meaningful phrase that is the way to problems coping in improving self-quality.

Many years ago, there was an Emperor, who was so excessively fond of new clothes, that he spent all his money in a dress. 
In the phrase above, it is told that "the emperor" trying to divert the problems that faced with how to buy a new clothes.

"The next day, when Jack woke up in the morning and looked out of the window, he saw that a huge beanstalk had grown from his magic beans! He climbed up the beanstalk and reached a kingdom in the sky. "

In this sentence, the phrase " looked out of the window " is a phrase that expresses that the problem can be solved. The phrase is a metaphor of diverting internal problems by looking at external situations.

"The next day, a wolf happened to pass by the lane where the three little pigs lived; and he saw the straw house, and he smelled the pig inside. He thought the pig would make a mighty fine meal and his mouth began to water."

In this paragraph, it appears that the figure of "the wolf" is a figure who has the opportunity to carry out selftransformation that is diverting self- problems. Figures "wolf" appears trying to cope from his problems, by way of entry into the house main character.

"There were other things in the stocking, nuts and oranges and a toy engine, and chocolate almonds and a clockwork mouse, but the Rabbit was quite the best of all."

In the paragraph above, it is told that the principal figures have the capability to do problems coping. It is indicated by the phrase "the stocking, nuts and oranges and a toy engine, and chocolate almonds and a clockwork mouse" which shows that the main character is trying to provide multi items as a means to cope the problem.

"The poor girl bore all patiently, and dared not tell her father, who would have rattled her off; for his wife governed him entirely."

In the data above, the dynamics of the problem is the ability of the possessed main character, namely Cinderella. For the problem above, then the figures principal despite dealing with the reality of the problems that problems in social economy.

"Oh, it is excellent!" replied the old minister, looking at the loom through his spectacles. "This pattern, and the colors, yes, I will tell the Emperor without delay, how very beautiful I think of them."

In the sentence above, it is more interpreted as an effort to interpret the phrase life. The sentence above shows that dynamics of problems is a part of life.

"Once upon a time there lived a poor widow and her son Jack. One day, Jack's mother told him to sell Reviews their only cow."

In the phrase "there lived a poor widow and her son Jack", emphasizing on the dynamics of the problem that is faced by an individual.

The phrase "to sell their only cow" shows that the dynamics of life though focused on the economic point below.

"The third little pig worked hard all day and built his house with bricks. It was a sturdy house complete with a fine fireplace and chimney. It looked like it could stand with the strongest winds."

In this paragraph, it told the problems faced by the characters in the story. The phrase "built his house with a brick" is a phrase that shows that the problem of a character that is no house is given a solution.

\subsection{Ability to Find Problems' Anchor}

Braga, Mello, et all (2012:136) state that the ability to analyze the problems' anchor is the ability to do an analysis of the problems' anchor. The ability to analyze the problems' anchor in the discussion topic is in line with the capability to anchor issues that faced the main character. The main problem analysis of a debate faced by the main character goes hand in hand with the ability to learn from a problem. The ability to topic analysis is the capability to conduct inventions in a structured way. The ability to find facts that are connected to one another. The ability to analyze the skills to solve problems is part of the ability to solve the problems at hand.

"THERE was once a velveteen rabbit, and in the beginning he was really splendid. He was fat and bunchy, as a rabbit should be; his coat was spotted brown and white, he had real thread whiskers, and his ears were lined with pink sateen. On Christmas morning, when he sat wedged in the top of the Boy's stocking, with a sprig of holly between his paws, the effect was charming."

In the paragraph above the hook "He was fat and bunchy, as a rabbit should be; his coat was spotted brown and white, he had real thread whiskers, and his ears were lined with pink sateen " shows the dynamics of the problem that is faced by the main character. The main character is told not to have the power to act.

"I will send my faithful old minister to the weavers," said the Emperor at last, after some deliberation, "he will be best able to see how the cloth looks; for he is a man of sense, and no one can be more suitable for his office than he is."

In the sentence above, the tendency to carry out improvements on concepts that are used by the king to use Meta-Analysis, which aims to look for anyone who 's best to carry out the task.

"Are you warm, maiden? ' he Replied. "

In the phrase above, using the question " are you warm Maiden " is an effort to carry out the analysis of the situation that is faced by opponents to talk.

\subsection{Ability to Do Strength Analysis}

Woods (2017:21) states that ability to do strength 
analysis in daily life is part of the capability to analyze the challenges faced by the main character. The ability to do an analysis of the strategies implemented is a skill to develop knowledge. The skills to analyze problems' background are the skills to analyze the potential problems that probably arise. The ability to problem analysis is part of the ability to problems' learning by elementary schools' students.

"Then King Frost stooped down, and bent over the girl, and the crackling sound grew louder, and the air seemed to be full of knives and darts"

This sentence shows that the ability to do meta-analysts is worth in character education.

"The grandmother lived out in the woods, half a league from the village, and just as the Little Red Riding Hood entered the wood, a wolf met her. Little Red Riding Hood did not know what a wicked creature he was, and was not at all afraid of him."

In the phrase above, Little Red Riding Hood does not know the creature that approached it. The phrase "did not know what a wicked creature he was" indicates that the character of Little Red Riding Hood is no process, Meta-Analysis were missing from the activity of these.

"The first little pig was very lazy. He didn't want to work at all and he built his house out of straw. The second little pig worked a little bit harder but he was somewhat lazy too and he built his house out of sticks. Then, they sang and danced and played together in the rest of the day."

In this paragraph, there seems to be a comparison of meta-analysis skills between characters. The third character in the story has the ability to meta-analysis, which is different from one to another.

\subsection{Ability to Do Opportunity Analysis}

Woods (2017:22) states that ability to conduct opportunity analysis goes hand in hand with the ability to analyze the impact of an event. In this case, the skills do an analysis of the phenomenon at hand. The ability of event analysis encountered by the time of students' learning transformation. The capability to observe the situation faced by the community. The ability to carry out a factors analysis which is the impact of changes.

"One egg is not hatched yet," said the duck, "it will not break. But just look at all the others, are they not the prettiest little ducklings you have ever seen? They are the image of their father, who is so unkind, he never comes to see."

The phrase above shows that character is doing a meta-analysis of the problems that exist to the main character. This is shown in the phrase "it will not break. But just look at others" which shows an analysis of the patterns that occur between one egg with another egg.
"It was lovely summer weather in the country, and the golden corn, the green oats, and the haystacks piled up in the meadows looked beautiful."

The sentence above shows their meta-analysis. This is shown from the description that appears in the phrase "the haystacks piled up in the meadows looked beautiful".

"They were mightily delighted at this invitation, and were wonderfully busy in choosing out such gowns, petticoats, and head-clothes as might become them.“

In terms of this, the characters in the story are told they are doing mapping or mapping of the problem. The selecting of attributes to be used at the party shows that mapping the problem and the solution is the main focus in a story.

"'Well, maiden,' he snapped out, 'do you know who I am? I am King Frost, king of the redoes. "'

The phrase above, the protagonist introduces himself to the reader. In the story above, the protagonist figure makes the mapping problem to the problems that the partners said. It appears from ways to introduce themselves using the phrase "snapped out".

"There lived a giant and his wife. Jack went inside the house and found the giant's wife in the kitchen. Jack said, "Could you please give me something to eat? I am so hungry! "

The sentence demonstrates mapping of the problems faced by Jack. Prominent men map out problems in themselves alone and ask for food as a solution to the problems that are faced.

"A good quarter of a league farther in the wood. Her house stands under the three large oak- trees; the nut-trees are just below. You must definitely know it," replied Little Red Riding Hood."

The sentence above shows the mapping ability of the Little Red Riding Hood character. The ability for mapping is described in the form of the skill to give instructions towards the "wolf".

"One day her mother said to her," Come, Little Red Riding Hood, here is a piece of cake and a bottle of wine. Take them to your grandmother, she is ill and weak, and they will do her good. "

In the sentence above, there is a mapping of the problems that are faced by a family.

"Once upon a time there was an old mother pig who had three little pigs and not enough food to feed them. So when they were old enough, they sent them out into the world to seek their fortunes."

In this sentence, mapping the problem becomes the focus. The meaning of the phrase "to seek Reviews their fortunes" is a metaphor of skill in doing the mapping is a part of life skills.

"For a long time he lived in the toy cupboard or on the 
nursery floor, and no one thought very much about him. He was naturally shy, and being only made of velveteen, some of the more expensive toys quite snubbed him."

The paragraph above shows that the ability to mapping the problem is part of the skill that is possessed by the main character. In mapping the problem, the main character is told to have the ability to make a description of the problem at hand.

"The mechanical toys were very superior, and looked down upon everyone else; they were full of modern ideas, and pretended they were real. The boat model, who had lived through two seasons and lost most of his paint, caught the tone from them and never missed an opportunity of referring to his rigging in technical terms."

This paragraph indicates that the mapping problem is an ability which is possessed by the main character. It is seen from the exposure of how work equipment is an ability which is possessed by the main character.

\section{Discussion}

Cooke (2017:48) states that performance skills in the resilience process are the ability to perform problem analysis that has been growing. In line with the student's mental development, resilience is a necessity owned by individuals to build individual learning conformity. In terms of building individual learning conformity, resilience skills are to develop the skills to undertake efforts to maintain conformity themselves in the learning process to teach. Learning conformity in the learning process to teach is a factor key to perform the acquisition of the teaching materials. In terms of increasing the ability of a student to do the process resilience, the skills to carry out the learning process are the dominant factors and help create the teaching and learning process that is following the demands of the times.

\subsection{Self-Conformity in the Learning Process in Primary Schools}

Cooke (2017:48) states the learning process to teach in a school base is an ability that is obtained from the integration learning process to teach. In the process of developing abilities and self- skills, the ability to understand the process being integrated with the conditions of the community is a necessity, although learned in the learning process in the elementary school environment. The capability development process in literature study is an ability which should be owned by the teacher. Thus, the ideas above could be seen in Table 1 .

The capability to conduct resilience process is the ability to understand the skills process which includes the process of developing abilities in terms of skills to think following the literary process in elementary school. In terms of this, it is an increase in the self-skills although passed by the learners in the neighborhood school basis.

\subsection{Increased Individual's Ability to Adjust the Discussion Topic}

Pendall, Foster, \& Cowell (2010:71) state that ability to adjust the topic conversation is a factor that is even considered. Individuals who have the ability in terms of resilience despite learning are able to accept the abilities and skills that are exemplified from children's stories. Thus, the ideas above could be seen in Table 2 .

Children's story who themed the ability for resilience is the children's story that is based on the ability of individuals in terms of accepting themselves or individuals. Receiving a shortage of individuals is a factor that is not able to be released from resilience, which is based on processing skills and the ability to conduct a study of the self itself. In terms of improvement capabilities and self-skills, the individual even adjusts with the ability that is developed to carry out a study of literature children. Resilience topic over many teaches the ability of individuals to adjust the topic conversation.

Table 1. Taxonomy of Self-Conformity in the Learning Process in Primary Schools

\begin{tabular}{|c|c|c|}
\hline Being Communicative & Being Attractive & Being Open Minded \\
\hline involving the physical presence & Being friendship & Recognizing others idea \\
\hline Yielding to group value & Giving certain types of idea & Share new ideas \\
\hline Acquiring a group acceptance & Have attractive body language & Developing the life goals \\
\hline Internalizing the norms. & $\begin{array}{c}\text { Being active to reach better forthcoming } \\
\text { opportunity }\end{array}$ \\
\hline
\end{tabular}

Table 2. Taxonomy of Increased Individual's Ability to Adjust the Discussion Topic

\begin{tabular}{|c|c|c|}
\hline Mastering Discipline & Managing Self Control & Preparing Precisely \\
\hline Improving the argument quality & Exchanging the knowledge & Focusing on the progress \\
\hline Rationing the ideas & Controlling the ego & Discussing the ideas \\
\hline Avoiding Arrogances & Thinking Creatively & Producing the new knowledge \\
\hline Convening Others & Working together & Creating general values. \\
\hline
\end{tabular}




\subsection{The Skills for Carrying out a Self- Adaptation Process}

Sools \& Hein Mooren (2012:2) state that resilience is an ability that puts on the analysis of the skill that develops with the ability to perform the process adaptation. Skills are developed in the process resilience which is closely related with the development skills to perform the adjustment yourself with the environment. The capability development process in conducting literary analysis is part of the ability to carry out an analysis of developing self-potential in the development process for individuals and the characteristics of the children's stories which are taught in the classroom. Thus, the ideas above could be seen in Table 3 .

Topics that were developed in the children's stories that are taught in the classroom focus on the skills to develop a process internalization themselves to the process development of the characteristic people each respectively. Skills to perform resilience are learning to develop the ability to adapt themselves.

\subsection{The Ability to Make Self Existence in the Learning Process}

Ewert \& Yoshino (2011:36) state that the development process of the individual and identity self, develop skills for the existence of the self in the learning process is a factor that is used in the development skills literature in school basis. The ability to conduct resilience processes is the ability to develop creative processes for developing individuals in the elementary school environment. To perform the development process, the existence learning, characteristics development and self-identity is a process developing the skills that focus on the skills of each individual to process the learning materials. Thus, the ideas above could be seen in Table 4 .

In the development process the self-characteristics, the skills to develop the real based education in the teaching and learning process is an ability which is owned by the school teacher in elementary schools on the process resilience learning-based using the children's story. Resilience Learning-based is a skill to perform learning in showing self-existence.

\subsection{Enhancing the Skills for Conducting a Self - Actualization Process}

Ewert \& Yoshino (2011:37) state that the ability to carry out the process self - actualization is a process developing individual character. Resilience skills processes are closely related to the ability to develop mental endurance in the process self - actualization. In the process of mental development and self-actualization, resilience capability which has been taught in the children's story is a part that is not integral to developing characteristics individually which reflects an increase in the local culture. Thus, the ideas above could be seen in Table 5 .

The focus of development is the capability to perform resilience is the capability to conduct studies on the children's moral development. The individual who provides the opportunity to develop the characteristics is associated with the increase in learning process. Resilience capabilities are a skill to do in actualizing themselves following the conditions they are developing.

Table 3. Taxonomy of Skills for Carrying out a Self- Adaptation Process

\begin{tabular}{|c|c|c|}
\hline Being Adaptive to Changing & Respecting Others & Influencing Others \\
\hline Compassing the knowledge & Developing a new goals & Understanding the values of the group \\
\hline Improving the consciousness & Determining impact factors & Questioning on new information \\
\hline Utilizing the information & Working effectively & Having a self-awareness \\
\hline Spreading the public data & Describing the context to the others & Working intelligently \\
\hline
\end{tabular}

Table 4. Taxonomy of Self Existence in the Learning Process

\begin{tabular}{|c|c|c|}
\hline Involving others to learn & Learning Continually & Following the Process \\
\hline Defining the new understanding & Memorizing the values & Illustrating the concept \\
\hline Describing the life based learning & Locating the source of the knowledge & Recitation the key points \\
\hline Illustrating the ideas & Recording the progress & Listing the ideas \\
\hline Interpreting the message & Explaining the message to others & Quoting other people works wisely \\
\hline
\end{tabular}

Table 5. Taxonomy of Conducting a Self - Actualization Process

\begin{tabular}{|c|c|c|}
\hline Respecting Others & Having Self Esteem & Thinking Positively \\
\hline Reframing the others' behavior & Inferring the self-awareness & Adapting to the new circumstances \\
\hline Grading the priority & Developing the mindset & Inventing the new formulation \\
\hline Calculating the risk & Growing the maturity & Developing the new treatment \\
\hline Creating an empathetic & Rising to be prudent & Reacting in an appropriate way \\
\hline
\end{tabular}




\subsection{Ability for Self-Acceptance}

Sheffi (2005:2) states that skill to conduct resilience processes is the ability to improve skills in terms of individual abilities. In terms of improvement skills, the ability to perform analysis on the performance of the individual becomes a reflection of the process self-acceptance. In the process of self-acceptance that is based on the ability to conduct resilience, the skill to make changes is part of the ability to carry out an analysis self transformed processes in daily life. The introducing process in a resilience process is a part development stage on elementary school-age children. Thus, the ideas above could be seen in Table 6 .

Resilience is part of the development process for competition in the global era. The resilience capability is closely related to the ability to perform self-acceptance on the condition that is encountered.

\subsection{The ability to Analyze Cause and Effect}

Randall, Baldwin, McKenize-Mhor, Mc Kim \& Furlong (2015:155) state that the skills to conduct resilience processes are factors in the development abilities and skills. In the process of developing resilience, facts were developed from children's stories that carried out the analysis, the process, the abilities and skills of individuals. In terms of the development of the ability, the following skills of individuals show that resilience is a factor that allows character development for the individual. Thus, the ideas above could be seen in Table 7 .

Individuals respectively put forward the development relations meaning in each item that exists in the story -based resilience that exists in the children's story. The development process based on ability to conduct resilience is an effort to develop characteristics that reflect the needs in the process of developing individual characteristics. The ability to conduct resilience is a process analysis cause and effect.

\subsection{Skills for the Problems Interpretation}

Woods $(2017: 21)$ states that the ability and skills to conduct analytical studies are a factor to be considered in the process of developing the ability to conduct resilience. In the process of character education and self-identity, the skills to carry out the process resilience is an ability that is unique and even learned in life. Thus, the ideas above could be seen in Table 8 .

In the development process resilience capability, learning factors to interpret the problem is partly a learning process that emphasizes on the development characteristics and individual self-identity. The self-development practice is closely related to the skills that are owned by an individual to perform resilience based on problem settlement. The ability for resilience is a process to do the meta-analysis followed by encountered problems. Resilience is the ability to increase the capability problems' coping.

Table 6. Taxonomy of Self-Acceptance

\begin{tabular}{|c|c|c|}
\hline Seeing Positively & Familiarizing with Others & Aware on the Problems \\
\hline Summarizing the viewpoints & Inferring the self-analysis & Illustrating the perception \\
\hline Comparing the designs & Developing the outlook & Recitation the impression \\
\hline Associating the thoughts & Growing to the adulthood & Listing the values \\
\hline Expanding the others interpretation & Escalating to be careful & Being honest \\
\hline
\end{tabular}

Table 7. Taxonomy of Analyze Cause and Effect

\begin{tabular}{|c|c|c|}
\hline Considering the Audience & Speaking Wisely & Updating the Knowledge Recourses \\
\hline Summarizing the philosophies & Comparing the ideal notion & Distinguish the ideas \\
\hline Comparing the notions & Contrasting the key structure & Extending the mindfulness \\
\hline Associating the concepts & Explore the perception & Representing the new cognizance \\
\hline Expanding the others people points of view & Producing the new method & Generating new life environment \\
\hline
\end{tabular}

Table 8. Taxonomy of Problems Interpretation

\begin{tabular}{|c|c|c|}
\hline Interpreting the Data & Designing the Solution & Interpreting the Message \\
\hline Solving the problems & Applying the idea & Representing the real example \\
\hline Discovering the solution & Demonstrating the knowledge & Generating new setting \\
\hline Reporting the process & Producing the designs & Doing the best \\
\hline Preparing the new plan & Administer the procedure & Expanding the knowledge \\
\hline
\end{tabular}




\section{Conclusions}

Resilience is a process that is used for problems' coping. In mental development of problem coping, individual skills play an inseparable part of the ability to do resilience. In this case, the ability to do resilience needs to be taught from elementary school age. The process of developing abilities for resilience is being taught in the form of short stories. Short stories for children are based on the ability of individuals to do the ability to analyze data and facts that are developed based on the idea of resilience that is developed for each character in the story.

\section{Acknowledgements}

This research was assisted by several individuals to collect data. First is Arya Taufiqqurahman graduated from Universitas Surabaya, Aditya Nur Arrifin graduated from of Institut Teknologi Adhi Tama Surabaya, Fahrul Yudatama, a student in Universitas Brawijaya who has helped survey a film and stories that are trending among children.
[9] Vale, L. J., \& Campanella, T. J. (2005). The resilient city: How modern cities recover from disaster. Oxford University Press.

[10] Woods, D. D. (2017). Essential characteristics of resilience. In Resilience engineering (pp. 21-34). CRC Press.

\section{REFERENCES}

[1] Braga, L. L., Mello, M. F., \& Fiks, J. P. (2012). Transgenerational transmission of trauma and resilience: a qualitative study with Brazilian offspring of Holocaust survivors. BMC psychiatry, 12(1), 134.

[2] Cooke, P. (2017). Resilience in ruins: The idea of the 'arrested dialectic'in art after resilience's failures. European Planning Studies, 25(1), 48-66.

[3] Ewert, A., \& Yoshino, A. (2011). The influence of short-term adventure-based experiences on levels of resilience. Journal of Adventure Education and Outdoor Learning, 11(1), 35-50.

[4] Krippendorf, Klaus. 1984. Content Analysis: An Introduction to Its methodology. Beverly Hills: Sage Publications

[5] Pendall, R., Foster, K. A., \& Cowell, M. (2010). Resilience and regions: building understanding of the metaphor. Cambridge Journal of Regions, Economy and Society, 3(1), 71-84.

[6] Randall, W., Baldwin, C., McKenzie-Mohr, S., McKim, E., \& Furlong, D. (2015). Narrative and resilience: A comparative analysis of how older adults story their lives. Journal of aging studies, 34, 155-161.

[7] Sheffi, Y. (2005). The resilient enterprise: overcoming vulnerability for competitive advantage. MIT Press Books, 1 .

[8] Sools, A., \& Hein Mooren, J. (2012). Towards Narrative Futuring in Psychology: Becoming Resilient by Imagining the Future. Graduate journal of social science, $9(2)$. 